\title{
LA VÍA ROMANA DEL NAJERILLA: UNA INTRODUCCIÓN A SU ESTUDIO
}

\author{
THE ROMAN ROAD OF NAJERILLA: \\ AN INTRODUCTION TO ITS STUDY
}

\author{
Adrián Calonge Miranda* \\ Universidad del País Vasco / Euskal Herriko Unibertsitatea, Vitoria-Gasteiz
}

\begin{abstract}
RESUMEN. En este trabajo se ponen de manifiesto evidencias que demuestran la existencia de una vía romana secundaria de comunicación que enlazaba la ciudad de Tritium Magallum (Tricio, La Rioja) con la civitas de Nova Augusta (Lara de los Infantes) a través del paso natural de Canales de la Sierra (La Rioja). Gracias a los datos aportados por el comercio de cerámica tritiense, el estudio de las minas de metal de la Demanda y la pervivencia de esta por el valle del Najerilla en época medieval, abordaremos el trazado y la utilidad de esta vía de carácter secundario.
\end{abstract}

PALABRAS CLAVE: vía romana, Tritium Magallum, Nova Augusta, Valle del Najerilla.

ABSTRACT. This work shows several archeological evidences which demonstrate the existence of a Roman road linking Tritium Magallum (Tricio, La Rioja) with Nova Augusta (Lara de los Infantes) through the natural crossover of Canales de la Sierra (La Rioja). Thanks to the data provided by the Tritian ceramic trade, the study of the metal mines surrounding the "Sierra de la Demanda» and the survival in the medieval times of this road through the Najerilla valley, we will approach the route and the usefulness of this secondary road in Roman times.

KEYWORDS: Roman road, Tritum Magallum, Nova Augusta, Najerilla valley.

* Correspondencia a / Corresponding author: Adrián Calonge Miranda, Universidad del País Vasco (UPV/EHU). Facultad de Letras. Paseo de la Universidad (01006 Vitoria-Gasteiz) - adrian.calonge@ehu.eus - https://orcid.org/0000-0001-5701-7450.

Cómo citar / How to cite: Calonge Miranda, Adrián (2019), "La vía romana del Najerilla: una introducción a su estudio», Veleia, 36, 183-205. (https://doi.org/10.1387/veleia.19534).

Recibido: 1 abril, 2018; aceptado: 24 mayo, 2018.

ISSN 0213-2095 - elSSN 2444-3565 / (C) 2019 UPV/EHU

(c) (i) Esta obra está bajo una licencia

Creative Commons Atribución 4.0 Internacional 


\section{INTRODUCCIÓN}

El presente trabajo pone de manifiesto diferentes evidencias que demuestran la existencia de una calzada romana de carácter secundario que seguía uno de los cauces tributarios del Ebro: el río Najerilla. Esta vía partía de la ciudad de Tritium Magallum (Tricio, La Rioja) y seguía el curso ya mencionado hasta alcanzar la localidad de Canales de la Sierra donde terminaba de superar el Sistema Ibérico, y bajaba por la margen sur de esta cordillera alpina buscando la cuenca hidrográfica del Duero a través del río Arlanza para alcanzar el territorium de la civitas de Nova Augusta (Lara de los Infantes, Burgos). Nos vamos a centrar en un territorio situado en el sector occidental de la actual Comunidad Autónoma de La Rioja y en el Partido Judicial de Salas de los Infantes, al sureste de la provincia de Burgos (Castilla y León).

El valle medio del Ebro y la Meseta, pese a la dificultad que planteaba la cordillera alpina, estuvieron conectados en época romana con ejes viales secundarios trasversales norte-sur. Eran caminos que aprovechaban los ejes de penetración naturales que formaban los diferentes valles fluviales y los puertos de montańa para facilitar el tránsito de personas y mercancías.

Graccurris (Alfaro, La Rioja), Calagurris Iulia Nassica (Calahorra) (Pascual \& Pascual 1984, 109-111), Vareia (Varea, Logroño) (Espinosa, 1994b, 137-144) y Tritium Magallum (Tricio, La Rioja) eran puntos de partida de vías secundarias que remontaban los ríos Alhama, Cidacos, Iregua y Najerilla respectivamente para poder alcanzar la meseta.

Estos caminos transversales debieron estar ya en uso en época prerromana y sirvieron para que las tropas romanas avanzasen en la conquista de la zona en el siglo iI a.C. El ejemplo mejor documentado es la vía del Alhama-Linares, que enlazaba el actual término municipal de Alfaro con $\mathrm{Nu}$ mancia (Garray, Soria). El camino partía de la centuriación de Graccurris siguiendo el curso del río hacia el sur para alcanzar Contrebia Leukade (Aguilar del Río Alhama, La Rioja) donde se ha conservado parte del firme en sus accesos. A partir de aquí, continuaría hacia la provincia de Soria buscando el acceso a Numancia (Romera 2012, 274-284). Además, contamos con una prueba epigráfica de la existencia de esta calzada secundaria: un exvoto a los Lares Viales que se encontró en el siglo xviII en Cervera de Río Alhama, y que actualmente se encuentra desaparecida ${ }^{1}$.

\section{El eje Najerilla-Arlanza: unión natural entre el Ebro y la Meseta}

El río Najerilla es considerado como el más importante de la red tributaria del Ebro dentro de la actual Comunidad Autónoma de La Rioja. Su cuenca tiene una extensión de $1.099 \mathrm{~km}^{2}$ y se desarrolla en el sector occidental la región. Constituye uno de los siete valles riojanos que nacen en el Sistema Ibérico y desembocan en el Ebro. Tiene una longitud de 99,79 km desde su nacimiento en Canales de la Sierra hasta su final en Torremontalbo.

El nacimiento de este río se produce en la vertiente meridional de la Sierra de la Demanda y bebe de las lagunas glaciares en la zona de Neila. En Canales de la Sierra se unen el Neila con otros cauces menores que conforman el curso principal. En sus primeros kilómetros se desarrolla un valle amplio que sigue el eje sinclinal de Canales de la Sierra, situación que contrasta con el paisaje de montaña que nos ofrecen las Sierras de San Lorenzo y las Viniegras. Esta disposición se mantiene hasta Mansilla, pero el sector entre esta localidad y Anguiano es completamente diferente. Los ma-

${ }^{1}$ CIL II 2987; ILER 584; ERRioja 3. 
teriales, de origen paleozoico, son más duros, con lo que la red fluvial se encaja con valles estrechos y laderas con fuertes pendientes.

A partir de Anguiano, entra en la Depresión del Ebro por lo que nos encontramos ya ante un valle que se va volviendo más amplio y más llano hasta su desembocadura en Torremontalbo. La red fluvial se completa con cauces que desaguan en el Najerilla. En la margen izquierda destacan el Tobía, el Cárdenas y el Tuerto, mientras que por la margen derecha están el Pedroso o el Yalde. Debemos también añadir una gran cantidad de arroyos y barrancos, especialmente en el curso alto del río.

El Arlanza nace en la Sierra de Neila, pero, en esta ocasión, nos vamos a centrar en uno de sus ríos tributarios: el Pedroso. Posee una longitud de 27,8 kilómetros desembocando en el Arlanza. Su nacimiento se produce también en la Sierra de la Demanda entre los picos de San Millán, Torruco y Cabeza Aguilaz en Casa de la Sierra. Posee una dirección noroeste-suroeste hacia la Meseta. Como veremos, también es muy interesante el curso del Tejero-Quintanilla para el trazado de la vía ya en tierras burgalesas. Con todo, la conexión entre ambos valles es clara a través de la actual localidad de Monterrubio de la Demanda.

En 1983, María Ángeles Magallón (1983, 160-161) apuntó a la posibilidad de un punto de unión terrestre entre las civitates de Tritium Magallum y de Colonia Clunia Sulpicia en base a los restos arqueológicos de origen romano que se habían encontrado a lo largo del curso najerense. La misma autora junto a Enrique Ariño (Ariño \& Magallón 1991-1992, 448) aumentaron los argumentos con la inclusión de la importante industria alfarera del foco tritiense, la epigrafía encontrada en el Sistema Ibérico riojano y la descripción que José Antonio Abásolo (1978, 33-35) realizó de un eje viario entre la capital conventual cluniense y la localidad riojana de Canales de la Sierra.

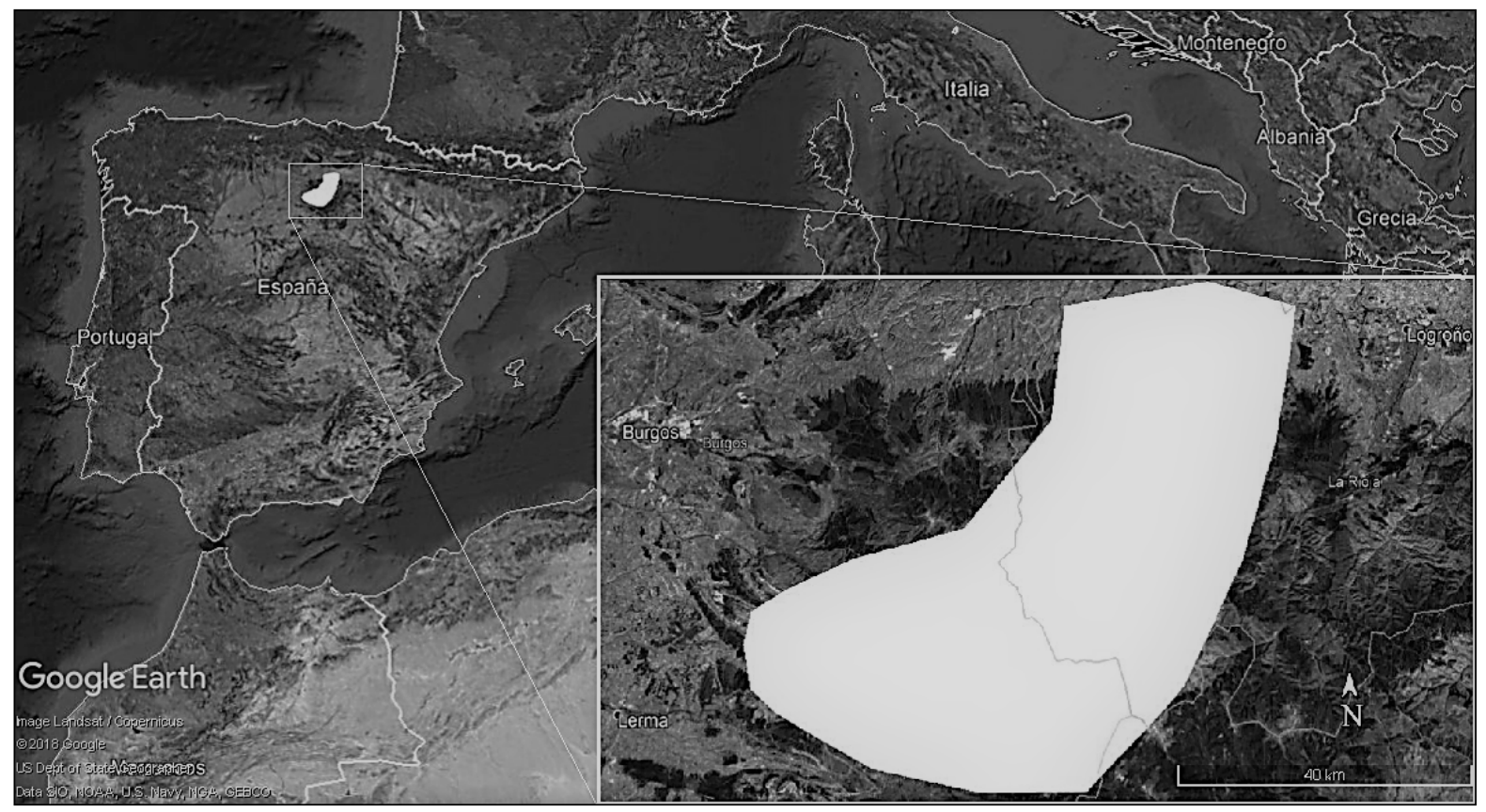

Figura i. Zona de estudio entre el Najerilla y el Arlanza (Fuente: elaboración propia/Google Earth). 


\section{TRitium Magallum y Nova Augusta. Dos ciudades conectadas POR UNA VÍA SECUNDARIA}

Tritium Magallum (Tricio, La Rioja) y Nova Augusta (Lara de los Infantes, Burgos) son las civitates que estarían conectadas mediante el uso de esta vía de carácter secundario a través del eje Najerilla-Arlanza. Esta última serviría también para enlazar la capital conventual, Clunia, con el valle del Ebro usando el curso del río riojano que estamos estudiando.

En la actual localidad de Tricio (La Rioja) se situaba la ciudad de Tritium Magallum, que se convirtió a partir de la época julio-claudia ${ }^{2}$ en uno de los principales focos de producción cerámica $^{3}$ de la zona norte de la península ibérica. Tras la conquista romana la civitas extendió sus límites más allá del antiguo oppidum berón hacia el noreste, y por el este alcanzó los límites de la

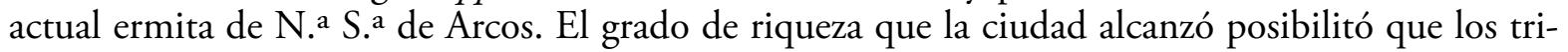
tienses levantasen un edificio monumental de carácter religioso. En el interior del actual templo se reutilizaron grandes tambores procedentes de esa construcción romana.

Parece que alcanzó la promoción jurídica durante la época flavia gracias a la concesión del Ius Latii y que comenzó a plasmarse en la epigrafía ${ }^{4}$. La ciudad continuó su desarrollo durante todo el periodo romano mencionándose como mansio de la calzada De Italia in Hispanias ${ }^{5}$ y apareciendo en la epístola del Papa Hilario en el siglo v d.C. ${ }^{6}$ Tritium fue perdiendo población a final del periodo romano y durante la alta edad media porque se desplazaba hacia Nájera, que tenía una posición de más fácil defensa.

Gracias a los estudios de Cristina Novoa y Carmen Alonso, conocemos el entorno más cercano a la civitas tritiense, especialmente en lo referente a los complejos alfareros ${ }^{7}$ y al poblamiento ru$\mathrm{ral}^{8}$. Novoa describe el desarrollo urbano con hornos ya excavados en la zona sur, dos yacimientos suburbanos, parte del entramado pseudo-reticular y la posible salida junto a la ermita de Arcos; en el extremo nordeste se localiza una domus, posiblemente una villa romana, a la que se asocian un complejo alfarero; y un gran edificio circular junto a la entrada norte.

2 Urbano Espinosa reconstruyó de manera teórica cuatro generaciones de una familia (los Mamili) de alfareros a partir de la epigrafía y diferentes marcas de alfareros. Gracias a la fecha de cada una de las referencias, pudo dar una cronología aproximada de cada uno de los miembros (Espinosa 1988, 271).

3 Sobre la comercialización de las cerámicas producidas en el entorno tritiense: Garabito 1978, 577-586.

4 En la epigrafía quedó plasmado este cambio de estatus jurídico, como en el epitafio de Lucio Memmio Probo (CIL II 2892; ERRioja 25; HEp 1, 1989, 516; AE 1987, 617) donde se menciona "Res Publica Tritiensium» o la adscripción de sus habitantes a la tribu Quirina.

5 De Italia in Hispanias: It. Ant. 387.4-395.4; el tramo riojano corresponde a 392.2-394.3.

6 Epístola donde menciona a los nobles y grandes propietarios que le habían enviado una misiva defendiendo al obispo Silvano de Calahorra ante una querella que se había creado contra él en el Concilio Provincial (Castellanos 2011, 37-40).
7 Dentro del término municipal de Tricio se han realizado investigaciones en El Quemao, Prado Alto, Rivas Caídas, Garrero, Los Pozos, La Alberguería y La Salcera. En las localidades más cercanas de Arenzana de Arriba, Arenzana de Abajo, Bezares o Majarrés. Un inventario y estudio sobre los yacimientos tipo alfar del complejo de Tritium Magallum lo podemos encontrar en Alonso \& Jiménez 2015, 117-126.

8 Gracias a la prospección aérea, Cristina Novoa localizó una serie de establecimientos rurales entre los que podemos destacar el de Prado de Abajo/El Rollo en el que se observa una estructura de planta central entorno a un peristilo de carácter monumental. Posiblemente se trate de una villa suburbana en la que se pueden observar las columnas del patio central y estancias con posible pavimentación de opus signinum (Novoa 2009, 200202). Ahora bien, aporta otros cinco yacimientos cuyas funciones aún no conocemos hasta que se practiquen futuras intervenciones y hace un repaso de las ya investigadas (Ib., 84-105 y 193-216). 
Tricio era una mansio de la vía De Italia in Hispanias9. Esta calzada conectaba con el foco minero del noroeste hispano, con Vareia que, según Plinio ${ }^{10}$, era el último puerto fluvial del Ebro; y con Caesaraugusta desde donde se tenía acceso al levante y a la Meseta. En Varea, además, podía enlazar con la vía que cruzaba Navarra de este a oeste ${ }^{11}$ y que posibilitaba su conexión directa con Pamplona ${ }^{12}$ y, de ahí, al puerto de Irún ${ }^{13}$. Y Urbano Espinosa describió otra calzada de carácter secundario que enlazaba el entorno tritiense con el controvertido Puente Mantible ${ }^{14}$ y la Varea berona (Viana, Navarra), punto de comienzo de la vía navarra ya aludida (Espinosa 1994b, 143).

$\mathrm{Al}$ sur de la Sierra de la Demanda, se encuentra la otra civitas que parece determinar el recorrido de la vía: Nova Augusta ${ }^{15}$. En el entorno de Lara de los Infantes se han localizado restos de cronología romana entre los que destacan muros con casi 1 metro de espesor, parte de lo que se ha interpretado como una red de cloacas, pozos de abastecimiento, materiales constructivos pétreos, restos cerámicos o ajuares de uso personal (Abásolo 2007, 133-135). Sin embargo, la principal fuente de información la constituyen más de 230 inscripciones localizadas en el entorno de la localidad burgalesa.

Se trata de epígrafes de piedra caliza o arenisca realizados en diferentes officinae del entorno de la ciudad. Realizaron diferentes temas decorativos como banquetes, escenas funerarias, ecuestres o geométricos en un periodo cronológico que abarcaba los tres primeros siglos de nuestra era $(I b$., 135-137). La información proporcionada nos habla de una sociedad que se integró poco a poco en el orbe romano hasta la consecución de la promoción jurídica en época Flavia $(I b$. , 144). De acuerdo con José Antonio Abásolo, el territorio de esta civitas localizada en Lara «era vecino al de Clunia - con la que limita al sur-y próximo, si no contiguo, al de otros núcleos de población, como Uxama al este, Belorado al norte y diferentes asentamientos del valle del Arlanza con Villavieja de Muñó, como más importante, al oeste (Ib., 125)».

Diferentes alfares fueron surgiendo en su entorno a partir de los siglos II y III. Fueron fabricando variadas producciones entre las que destaca la terra sigillata. Asimismo, el paso de los pueblos de origen germano dejó su impronta en la región como ejemplifica la ermita de Santa María en Quintanilla de las Viñas y vio cómo se desarrollaban las luchas entre cristianos y musulmanes mientras Nova Augusta se convirtió en una enorme cantera y era abandonada.

9 Contamos en el entorno tritiense con dos miliarios: uno de Claudio del año 43/44 procedente de Arenzana de Abajo ( $A E 1997,915$; HEp 7497; Espinosa 1994, 139; Espinosa \& Castillo 1995-1997,106) y otro de Claudio II (268-270) o de Tácito (275-276) encontrado en Tricio (CIL II 4879; ERRioja 74; HEp 10419; Govantes, 185; Espinosa 1986: 94).

10 Plin. Nat. 3.21.

11 Fue dada a conocer por primera vez en 1965 por Arias Bonet, quien veía una calzada entre Jaca y la Rioja Alavesa atravesando de oeste a este por la Navarra Media (Arias 1965, 181-187). Armendáriz y Velaza en 2006 afianzaron más el trazado incluyendo datos epigráficos que cinco décadas antes no se habían encontrado, como el de Arellano, que ellos mismos daban a conocer junto con otro anepígrafo (Armendáriz \& Velaza, 2006, 121-124).

12 Pérez 1985, 144-155 y noticia del hallazgo de pavimento en Nuin Cabello et al. 2016, 289-297.
13 Estrabón III 4.10.

14 En 1972, se publicó un estudio sobre este puente que conectaba ambas márgenes del Ebro entre El Cortijo (Logroño, La Rioja) y Assa (Lanciego, Álava) y cuya cronología se establecía en el siglo in d.C. Se trata de una infraestructura con siete arcos de diferente luz y un perfil alomado (Martín \& Moya 1972, 165-182). Sin embargo, en 2004, Isaac Moreno Gallo puso en duda la romanidad de Mantible por su semejanza con el puente románico de Puente Larreina (Navarra) y lo pone en relación con un camino medieval que uniría Pamplona con Nájera en el siglo XI (Moreno 2004, 66-72).

15 Gimeno Pascual y Mayer Olivé identifican Nova Augusta con Lara de los Infantes gracias a una relación de un epígrafe de Riotinto con otra de Barbadillo del Pez (Burgos) y Río Tinto (Huelva) (Gimeno \& Mayer 1993, 314-321). 
La ciudad se convirtió en un cruce de caminos. Según Isaac Moreno Gallo, esta civitas formaba parte de una calzada que partía de Numancia y finalizaba en Sasamón y que constituía un eje esteoeste al sur del Sistema Ibérico (Moreno 2011-2017b). Del mismo modo, tendría un enlace con Clunia, la capital conventual. Abásolo (Abásolo 1978, 33-35) ya teorizó con la existencia de una vía de carácter secundario que enlazaba la civitas de Peñalba de Castro con Tritium Magallum pasando por el partido judicial de Salas de los Infantes ${ }^{16}$.

\subsection{Los asentamientos rurales}

En el territorium de la ciudad de Tritium Magallum se construyeron varios focos productivos alfareros y hábitats suburbanos localizados principalmente en las zonas noreste, este y sur (Ariño \& Novoa 2007, 57-60). El patrón de asentamiento buscaba un correcto acceso al agua, vital tanto para la elaboración artesanal como para las actividades agropecuarias, como cerca de las vías de comunicación principales, secundarias y locales.

En el valle del Najerilla, se ha puesto el foco investigador en los complejos de hornos que formaron parte del centro productor tritiense. Hay ejemplos excavados en el entorno más inmediato a la ciudad romana ${ }^{17}$. Hacia el sur tenemos más testimonios como los dos hornos, uno de ellos perteneciente a un propietario llamado Claudius, localizados en Camprovín (Sáenz 1998, 150-151) o los restos de Santa Cruz en Baños del Río Tobía $(I b ., 151)$.

En los castros romanizados del curso medio y alto del Najerilla ${ }^{18}$ se dedicaron a actividades mineras, agrícolas y ganaderas. La presencia de restos pétreos de torcularia nos habla de asentamientos rurales en terreno menos abrupto y que se dedicaban a la elaboración de vino o de aceite. Dos son los contrapesos localizados: uno en el término de Turrios (Berceo) (Peña 2010, 609) y otro en Arenzana de Abajo ${ }^{19}$.

En territorio de la provincia de Burgos, dejando atrás el paso de Canales, y siguiendo el posible trazado de la vía, tenemos el yacimiento de Las Murallas junto a la ermita de la Vega en Huerta de Abajo $^{20}$. Justo enfrente, estará el castro romanizado de La Cabeza (Escalona 1995, 172-173 y 196). Una estela encontrada en el Valle de Vadelaguna (Bezares) pone en relación estos yacimientos con una necrópolis altoimperial que se encontraría al norte de la ermita ya señalada (Abásolo \& García 1980, 96-97).

16 Moreno Gallo en su planimetría de calzadas romanas de Castilla y León, traza esta conexión entre Clunia y Nova Augusta, pero no llega a describirla. (Moreno 2011-2017).

17 En Arenzana de Arriba, Arenzana de Abajo, Alesón, Manjarrés y Bezares (Alonso \& Jiménez 2015, 118-122).

18 Algunos de estos ejemplos son Los Bañuelos (Baños de Río Tobía), de Picolaicia (Viniegra de Abajo), La Teja (Mansilla de la Sierra) (Sánchez-Moreno 2010, 224) y el Cerro Cividad (Canales de la Sierra) (Taracena 1929, 28-31).

19 Se trata de un miliario de época de Claudio que, en época bajoimperial, fue reconvertido en un contrapeso para la producción de aceite (Castillo \& Espinosa Ruiz 1995-1997, 105-107).
20 Según Julio Escalona Monje, se trata de un yacimiento romano de carácter militar. La interpretación de recinto militar de protección se debe a tres factores: la proximidad al castro de la Cabeza al que atribuye una jerarquía superior con respecto al entorno; su ubicación sobre la vía hacia Tritium Magallum en el último valle antes de pasar a la Comunidad Autónoma de La Rioja y sobre la necesidad de que la ciudad romana que se encuentra bajo Lara necesitase un apoyo militar para su implantación (Escalona 1995, 199). Juan Antonio Abásolo y Rosario García en 1980 describían también los elementos defensivos, les atribuían una cronología altoimperial gracias a los restos cerámicos y hablaba de la posible existencia de un edificio de gran porte, posiblemente público, debido a restos suntuarios de fustes y basas de columnas (Abásolo \& García 1980, 55-56). 
En Castrovido, en el término El Castro, tenemos un poblamiento fortificado en altura prerromano del que conservamos parte del sistema defensivo, restos cerámicos y metalúrgicos de época celtíbera. También hay presencia de cultura material romana con cerámica común y terra sigillata hispánica, posiblemente de las primeras producciones tritienses (Ib., 40-45). Al este, en Monasterio de la Sierra, bajo el término de "Cabeza de San Vicente», hay un yacimiento bajoimperial de pequeña extensión $(50 \times 30 \mathrm{~m})$ en el que se han hallado restos de escoria, tejas y material cerámico ${ }^{21}$. Por último, en Salas de los Infantes se localiza un castro romanizado edificado en un escarpe entre dos barrancos y que dominaría el paso de la vía tratada (Abásolo \& García 1980, 81-83).

Para el área riojana es sumamente interesante el estudio de la epigrafía romana, como el denominado conjunto tritiense que constaba en 1986 con 19 inscripciones entre las que se encontraron en Tricio y en su área de influencia más inmediata ${ }^{22}$. Esto nos indica que la ciudad podía ejercer un control sobre el valle del Najerilla, aunque desconocemos la totalidad de su territorium o sobre los distritos rurales que podían quedar bajo su jurisdicción. Sin embargo, el conjunto de seis inscripciones de Canales de la Sierra tiene más conexiones con el área de la Meseta, especialmente con el conjunto de Lara de los Infantes (Espinosa 1986, 12-13).

\section{LA vía DEL NAJERILla. UNA vía SECUNDARIA DE IMPORTANCIA ECONÓMica}

\subsection{El papel de la comercialización de la cerámica tritiense}

El entorno de Tritium Magallum se convirtió en uno de los focos de producción cerámica más importantes de la península ibérica. Según Paz Peralta (Paz 2008, 505-507), los alfares tuvieron una vida activa de unos 445 años y no fueron uniformes ni en sus producciones ni en el volumen alcanzado. En un principio tuvieron una estrecha influencia de los talleres gálicos de los que pudieron incluso depender (Espinosa 1988, 263-272). Posteriormente fabricaron ya producciones propias, tanto en su decoración como en la tipología de las piezas que salían de sus hornos. El periodo de esplendor se correspondió con la etapa altoimperial. Nos debemos alejar de la idea de que, durante el bajoimperio, la producción cerámica del Najerilla fue residual. Durante los últimos ańos, se han descubierto nuevos alfares donde se pudo producir terra sigillata hispánica tardía en localidades como Berceo ${ }^{23}$, Badarán ${ }^{24}$, Cañas ${ }^{25}$ o Baños de Río Tobía ${ }^{26}$.

${ }^{21}$ Se interpreta como un establecimiento en altura para labores defensivas y de vigilancia (Abásolo \& García 1980, 74).

22 Área de influencia que Urbano extendía hasta la zona de San Millán de la Cogolla y Estollo, en el valle del Cárdenas (Espinosa 1986, 12).

${ }^{23} \mathrm{Se}$ encuentra estudiado mediante prospección. Se localiza en Campo/Prados donde se observa una gran cantidad de material en superficie M. M. Martínez González y S. Vitores Bañares publicaron una primera lista de materiales en 1999 (1999, 247-250) y se amplió un año después. De este último escrito, nos interesa la existencia de dos fragmentos del primer estilo y uno único del segundo (Martínez \& Vítores 2000, 341-342).

24 De Badarán hay constancia de varios yacimientos con presencia de abundante material cerámico como puede ser Vía Vacas (Martínez 1999, 242-247), Sobrevilla (Ib., 1999, 250-258; Martínez \& Vítores 2000, 342-349 y Pascual et al. 2000, 291-312), Peñalámina (Martínez \& Vítores 2000, 334, nota 4; y 337) y Aventines (Martínez \& Vítores 2000, 334-341). La cronología de todos estos yacimientos es amplia abarcando desde el siglo I d.C. hasta el v o vi d.C. a excepción de Peñalámina que únicamente ha proporcionado materiales altoimperiales.

De estos nos interesan especialmente Aventines y Sobrevilla. El primero ha proporcionado cuatro fragmentos de moldes del primer estilo. En Sobrevilla, se han querido ver los restos superficiales de 7 hornos y se han publicado un total 21 fragmentos de moldes del primer y segundo estilo incluido uno con una firma CARDIV (Pascual et al. 2000, 297-299). 
La comercialización de las cerámicas tritienses floreció por toda la península y alcanzó otras provincias romanas. Las producciones tritienses que se fabricaron en Tricio, Bezares y Arenzana de Arriba alcanzaron gran parte de la península, el norte de África, Italia, puntos de la Galia o la misma Britania. Mercados interiores muy importantes fueron la Lusitania, la Bética y en entorno del Valle del Ebro (Garabito 1978, 577-586).

La cercanía de la capital conventual cluniense, cuya ruta directa corresponde al valle del Najerilla, hizo de esta ciudad un mercado muy importante. F. Tuset y J. Buxeda realizaron un estudio sobre la terra sigillata hispánica avanzada en Clunia (Tuset \& Buxeda 1995, 355-363). Nos interesa su procedencia y su distribución cronológica. De esta manera, en la segunda mitad del siglo ir d.C., la mayor parte de las producciones consumidas en Clunia proceden de la zona del Ebro. Este dominio se sigue manteniendo durante algo más de 100 ańos puesto que en el tercer cuarto del siglo III d.C., las piezas procedentes de los alfares del Duero pasan a ser mayoritarias (Ib., 362). Por lo tanto, la capital conventual cluniense se abastecía de cerámica procedente del valle del Ebro en unos niveles que podemos considerar como importantes. El acceso más directo a la ciudad desde los focos tritienses se produce a través del valle del Najerilla ya que el resto de las posibilidades eran itinerarios más largos bordeando el Sistema Ibérico.

Más recientemente, se ha realizado un estudio comparativo entre los centros tritienses y los alfares de Uxama Argaela (El Burgo de Osma, Soria) debido a la gran similitud de la decoración de las piezas. Los autores proponen varias teorías para explicar esta analogía. No se han encontrado moldes riojanos en el yacimiento soriano, por lo que es posible que los talleres tritienses ejercieran un cierto control sobre los de Uxama Argaela en un primer momento. Tampoco se descarta que alfareros de Tricio o formados en los talleres del Najerilla pudieran haberse instalado la zona soriana. Teorías que, por el momento, no se han podido demostrar (Romero \& Romero 2016, 308-313). La cerámica najerense podía llegar mediante el enlace existente entre Clunia y Uxama Argaela y que ha sido estudiada por Moreno Gallo (Moreno 2011-2017a).

A partir del siglo III, se desarrollaron una serie de centros alfareros en el entorno del río Arlanza. Las condiciones de este lugar eran óptimas para estas actividades artesanales puesto que se encontraban con acceso a abundante agua, a vetas de arcilla y a abundante combustible gracias a los bosques que poblaban la zona (Pradales \& Gómez 2003, 84-85). En el entorno de Lara de los Infantes, se han encontrado indicios de alfares que van desde fragmentos de moldes para producir cerámicas decoradas con el segundo estilo de Mayet como los de la ermita de Santa María en

\footnotetext{
25 Alfar localizado en el término de «El Villar» en Cañas. En superficie hay una gran presencia de material cerámico entre el que destacan 12 fragmentos de moldes del primer estilo decorativo y 29 del segundo estilo (Ínigo \& Martínez 2002, 227-241 y 245-256). F. Pérez los relaciona con otros 12 fragmentos debido a "la coincidencia de ciertos motivos decorativos» con el 'Alfar Del Valle Medio del Najerilla' dados a conocer por M. E. Solovera y T. Garabito en 1990 (Pérez 2014, 155). L. Ińigo Erdozain y M. M. Martínez González hablan de una perduración de la producción hasta principios del siglo vi debido a la presencia de cerámica estampillada (2002, 260-261).

26 Se encuentra en el término de Santa Cruz en Baños de Río Tobía y se encuentra también investigado mediante una prospección en superficie. En superficie
}

aparecen abundantes fragmentos de cultura material romana entre los que destacan un total de 4 fragmentos de molde de terra sigillata hispánica con decoración geométrica o zoomórfica enmarcados en frisos con series de metopas y otros motivos decorativos. También se han encontrado fragmentos de terra sigillata, cerámica común y un posible carrete de alfarero con una altura de $4.4 \mathrm{~cm}$, un diámetro superior de 6.2 y $6.8 \mathrm{~cm}$ de diámetro inferior y fragmentos de cerámica común (De las Heras 1988, 62-97). De las Heras piensa que una estampilla (L...NVS / C...IS) encontrada en un fragmento de cerámica común pudo ser el nombre de uno de los alfareros que trabajaron en este taller (Ib., 91). La cronología de este taller, basada en las formas de las producciones, es amplia: entre mediados del siglo I d.C. y el siglo Iv de nuestra Era (Ib., 101-103). 
Quintanilla de las Viñas y el Alto de Lara (Pérez 2014, 158), hasta los complejos parcialmente excavados de la Colegiata en Covarrubias ${ }^{27}$ o de "El Cantarrillón», en el término municipal de Mambrillas de Lara ${ }^{28}$.

Durante diferentes obras de la N-234 en el término municipal Mambrilla de Lara, se han practicado varias intervenciones arqueológicas. Hasta el momento han proporcionado cinco hornos que llegaron a producir terra sigillata hispánica tardía lisa y decorada mediante el uso del segundo estilo de Mayet habida cuenta de 8 fragmentos de moldes encontrados dentro del horno 3. Estamos ante uno de los centros más antiguos de la provincia de Burgos ${ }^{29}$.

Esas fechas se aproximan a las aportadas en el estudio de J. Tusset y J. Buxeda en su investigación sobre Clunia y que determinaron que la mayor parte de las sigilatas consumidas en la capital conventual provenían de los focos del Duero. La vinculación de estos nuevos focos del Arlanza con los alfares del área tritiense parece evidente y la ruta directa entre ambas zonas es el valle del Najerilla a través del paso del Canales ${ }^{30}$.

\subsection{Una zona minera en el entorno de las 7 villas (Alto Najerilla)}

En el entorno de la comarca de las Siete Villas se desarrolló una industria de extracción y procesamiento de diferentes minerales. La referencia más antigua de actividad minera en esta zona del Alto Najerilla es del siglo $\mathrm{XVI}^{31}$. El apogeo de estas actividades mineras se produjo entre $1875 \mathrm{y}$ 1925 con diferentes explotaciones en Mansilla de la Sierra, Villavelayo, Canales de la Sierra, Ventrosa, Viniegra de Abajo, Monterrubio, Neila o Barbadillo de Herrera (Ezquivela 2009, 63).

Es complicado saber el origen del aprovechamiento de las galenas que florecían en la Sierra de la Demanda. No contamos con referencias en las fuentes clásicas ni con restos claros de época celtíbera o romana. Sin embargo, hay ciertos indicios que nos hacen sospechar de una explotación antigua de los filones de plata, plomo o cobre que se encontraban en esta comarca.

27 Los restos exhumados en el templo de San Cosme y San Damián de Covarrubias corresponden a un alfar del que se conservaron parte de una estructura de combustión, restos relaciones con hornos, un supuesto pórtico y un vertedero. De entre la abundante cultura material exhumada podemos destacar elementos de alfarero como punzones, terra sigillata hispánica tardía lisa y decorada a molde, fragmentos de moldes con el segundo estilo de Mayet, etc. (Pérez 2014, 160-163).

28 Durante diferentes obras de la N-234 en el término municipal Mambrilla de Lara, se han practicado varias intervenciones arqueológicas. Hasta el momento han proporcionado cinco hornos que llegaron a producir terra sigillata hispánica tardía lisa y decorada mediante el uso del segundo estilo de Mayet, habida cuenta de 8 fragmentos de moldes encontrados dentro del horno 3. (Ib., 163-164).

29 David Pradales y Julio Gómez estudiando el estilo de la sigillata tardía decorada, la categorizan como «estilo transicional», típico del siglo III d.C. (Pradales \& Gómez 2003, 84), cronología reforzada gracias a una moneda de Claudio II (268-370).
30 Fernando Pérez $(2014,170)$ se basa en los estudios de Tuset y Buxeda para escribir «Sabemos, además, por los trabajos de Frances Tuset y Jaume Buxeda que algunos alfareros, probablemente desplazados desde los centros riojanos, comenzaron a fabricar terra sigillata en el Valle del Duero hacia el año 200, ampliándose posteriormente el número de talleres».

David Pradales y Julio Gómez $(2003$, 85), por otro lado, hablando sobre el alfar de Mambrillas de Lara y su situación, plasman «este enclave artesanal, se dispone en una zona bien comunicada, cercano a la vía que conducía desde Clunia a Tritium Autrigorum y en la salida natural que, desde la cuenca del Najerilla por el valle del río Pedroso, se comunicaba con el valle del Arlanza. $\mathrm{Pu}$ dieron ser por tanto una derivación de alfareros de Tricio los que se asientan en la zona».

31 Un permiso de 1566 concedido a Juan Beltrán Sanguitó, vecino de Mansilla procedente del «Registro y Relación General de Minas de la Corona de Castilla» (Ezquivela 2009, 62). 
La actividad romana se debió dar en torno a las galenas argentíferas formadas en el terreno siluriano, especialmente, en la zona próxima a la zona del San Lorenzo, lugar donde hay filones de plomo y cobre que posiblemente fueron explotados ya en época prerromana, por los arévacos ${ }^{32}$, continuando tras la conquista romana.

En 1951, en el estudio sobre la historia de la minería riojana, Diego Ochagavía Fernández recoge galerías subterráneas en Mansilla de la Sierra de procedencia romana (Ochagavía 1951, 470471) y Claude Domergue en su estudio sobre las minas de la península ibérica durante la antigüedad, menciona dos posibles conjuntos mineros en el entorno del Alto Najerilla que producirían plata y plomo (Domergue 1990, 567).

Ruth Ayllón, dentro de su estudio sobre las cuevas, bosques y montañas sagradas de la Celtiberia, hace un repaso de los filones conservados en el entorno del pico del San Lorenzo, identificado como el monte Dercetius ${ }^{33}$, que considera como uno de los espacios sagrados más singulares (Ayllón 2015, 119).

De esta manera cita vetas de cobre y hierro junto al monasterio de Valvanera: en Picolaicia (Viniegra de Abajo) existían filones de plomo, hierro y cobre, y entre Mansilla de la Sierra, Villavelayo y Canales de la Sierra se encontraban 25 afloramientos de cobre y 3 de hierro. La autora piensa que en época romana podían estar en explotación unas seis minas (Ayllón 2015, 120-121). Además, gracias a la toponimia tenemos fosilizada esta riqueza en términos como Peñas del Oro o Santa Âurea (Villavelayo) (Ayllón 2015, 347).

Por último, hay que referirse al estudio de una estación siderúrgica localizada en el entorno del monasterio de Nuestra Señora de Valvanera y que dio a conocer en 1985 A. Madroñero (1985, 20-31). La cronología que el C14 aporta a este yacimiento está situada sobre principios del siglo viII, parece que antes de la intervención musulmana. El mismo autor señala la actividad metalúrgica en otras zonas cercanas, como puede ser Canales de la Sierra. Para S. Castellanos (1999, 74 ), este centro productivo avala la existencia de una actividad económica previa a las repoblaciones castellanas del siglo IX y ejemplifica el dinamismo económico que se desarrolló en el sector suroccidental de La Rioja durante la Antigüedad Tardía.

Estos metales debieron servir como materia prima para la acunación de diferentes monedas celtíberas cuyas cecas se han vinculado con el entorno del valle del Najerilla. El primero de los tres

32 Urbano Espinosa, en opinión verbal recogida por la edición digital del Diario La Rioja: «El foco minero lo explotaron los celtíberos, sobre todo los arévacos. En mi opinión, ello explica que los arévacos fueran capaces de sostener durante más de 20 años la confrontación militar con Roma. Todo ello les proporcionó armas y riquezas para la producción. Luego, Pompeyo favorece a los berones porque habían luchado a su favor y se desarrolla la minería».

(Fuente: www.larioja.com/pg060529/prensa/ noticias/Sociedad/200605/29/RIO-SUBARTICLE058.html, consultado el 18/01/2018)

33 Así lo demostraría un ara votiva incompleta descubierta en San Millán de la Cogolla, en el término de San Cristóbal en la ladera del Monte Castillo según Urbano Espinosa. Este mismo autor aporta también una descripción de esta y una explicación sobre la etimología y supervivencia del término: «El nombre Dercetius se forma con el radical indoeuropeo *derk- 'mirar', que vemos presente en diversos antropónimos hispanos. Pervivió hasta el siglo viI en el topónimo Dircertius Mons, al que, según S. Braulio de Zaragoza, se apartó San Millán. Se ha defendido que «el recuerdo de este nombre duró varios siglos, pues el monasterio (el de S. Millán) llevó el adjetivo Dercensis hasta 1010, en el que empezó a llamarse Vergegio (de donde Berceo)». Se deduce de ello que Dercetius o Dircetius es un monte, al que se rinde culto en época romana; para J. M. ${ }^{a}$ Blázquez se trataría de una deidad solar «que habitaba en las montañas igual que los restantes asimilados a Júpiter que se encuentran en la Península». Como adjetivación de la etimología citada significaría "el visible» y quizá por ello sea identificable con el monte San Lorenzo próximo, el más elevado de la Sierra de la Demanda" (Espinosa 1986, 59-60). 
ejemplos es Titiakos $^{34}$ de la cual conservamos cuatro variantes fechadas entre la segunda mitad del siglo II a.C. y principios del i a.C. Se trata de ases en cuyo anverso tenemos una cabeza masculina con o sin barba y, en el reverso, un jinete armado con una lanza, decoración con motivos vegetales y la leyenda en caracteres prelatinos. Se suele situar este centro emisor en Tritium Magallum, si bien hay quienes lo sitúan en El Villar en Bobadilla ${ }^{35}$.

Bajo la leyenda letaisama ${ }^{36}$ tenemos dos series cuya localización está en debate: Ledesma de la Cogolla o Ledesma de Soria. La primera está situada en el curso medio del Najerilla y se localiza a apenas unos kilómetros al este del ya mencionado yacimiento de El Villar en Bobadilla ${ }^{37}$. Estas monedas poseen un anverso con cabeza masculina sin barba y con motivos marinos y un reverso con un jinete con lanza y la leyenda. Se establece una cronología de principios del siglo i a.C.

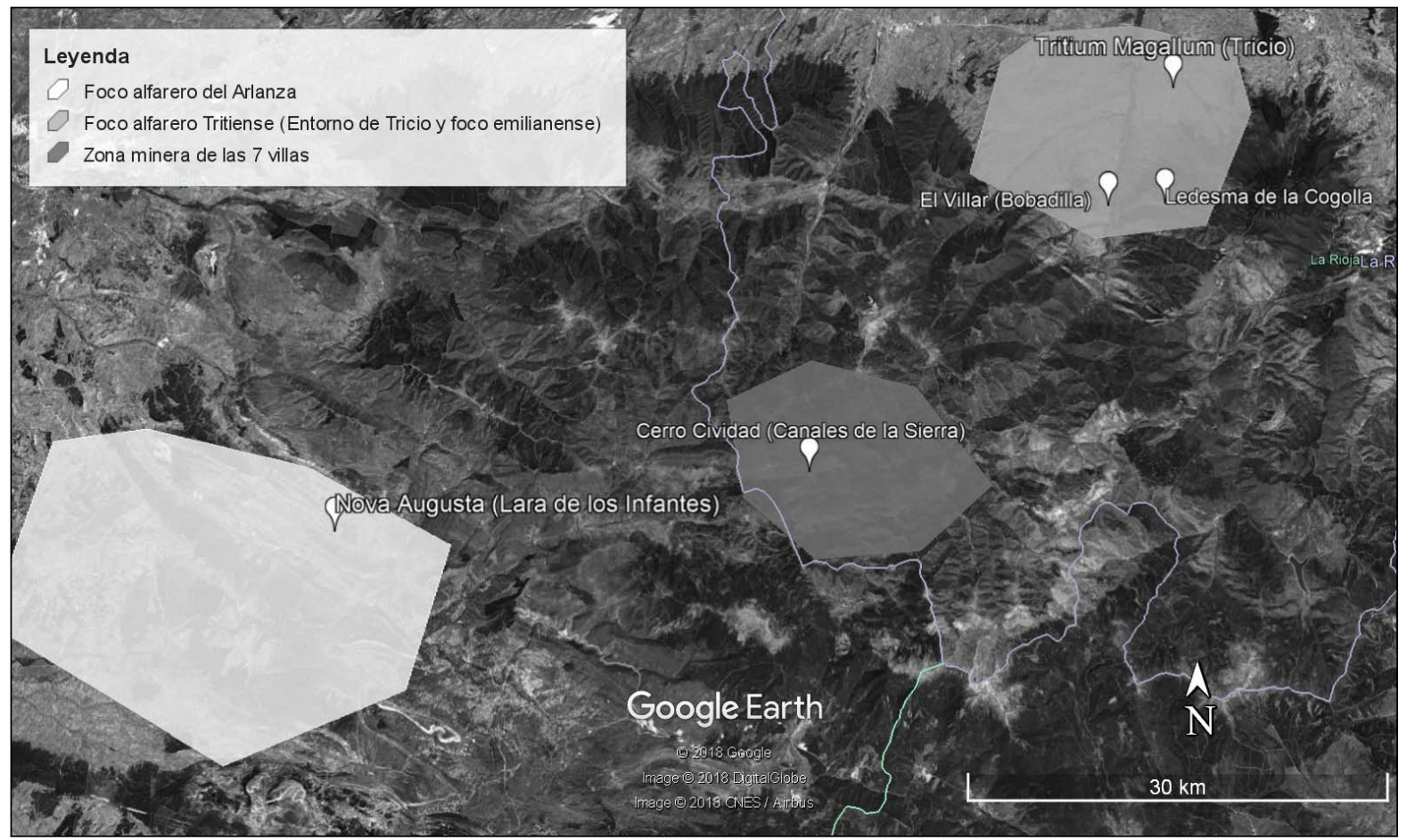

FIgURA 2. Focos productivos de época romana en el valle del Najerilla y en el Alto Arlanza (Fuente: elaboración Propia/Google Earth).

34 BDHesp, Mon. 58, consulta 11-01-2018.

35 Urbano Espinosa pensó que el núcleo berón dominante en el Najerilla no estaba situado en el cerro de Tricio, sino que se desarrolló en un lugar con un mayor desarrollo como pudo ser el poblado del Cerro Molino en Hormilla o El Villar en Bobadilla (Espinosa 1994a, 107).
36 BDHesp, Mon. 68, consulta 11-01-2018.

37 Es un potente oppidum berón que está dando materiales muy interesantes gracias a la presencia de unos hornos aún por excavar y abundantes restos cerámicos entre los que destacan grandes placas cuadrangulares y bloques prismáticos con decoración geométrica (Ceniceros 2017, 1668-1669). 
Por último, tenemos otra ceca que se ha querido localizar en Canales de la Sierra, en cuyo término municipal se encuentra el cerro Cividad que, tradicionalmente, se había identificado como la Segeda que recogían las fuentes ${ }^{38}$. Blas Taracena desechó esa teoría en 1929 en sus conclusiones sobre el yacimiento ${ }^{39}$. Tenemos una única serie que se ha propuesto, con dudas, que proceda de Canales de la Sierra. En el anverso tiene una efigie masculina barbada con motivos marinos y un jinete con lanza y la leyenda sekisamos ${ }^{40}$ en el reverso. Como en los casos anteriores, su cronología estaría situada en los comienzos del siglo i a.C.

La procedencia de estas tres cecas, como ya hemos podido observar, nos ha dado tres yacimientos de cronología prerromana a los que podemos sumar otros ejemplos como Picolaicia en Viniegra de Abajo, La Teja en Mansilla de la Sierra o Los Bañuelos en Baños de Río Tobía (SánchezMoreno 2010, 224). Estos poblados a lo largo del río Najerilla nos permiten proponer que la vía del Najerilla era ya usada en tiempos prerromanos junto con la posible explotación de las vetas mineras.

\section{Trazado y Restos CONSERVADOS}

1. Iniciamos la descripción del trazado de esta vía secundaria en Tritium Magallum pero no podemos descartar que continuase hasta la desembocadura del río, tal como parecen confirmar las fuentes medievales. Tricio estaba conectado con la calzada principal de la región, De Italia in Hispanias mediante un doble empalme de entrada y salida ya que esta arteria pasaba por el norte ${ }^{41}$.

2. La salida sur de la ciudad correspondería con el inicio de la calzada secundaria que estamos estudiando. Cristina Novoa Jáuregui (2009, 286-287 y 296) identificó como posible salida sur de la civitas de Tritium Magallum a una vía medieval que enlazaba Tricio con Arenzana de Abajo (Cantera 1991, doc. 13, 24). El entorno tritiense se configura como un punto económico muy dinámico no solo por la existencia de los complejos alfareros sino también con una gran cantidad de explotaciones agropecuarias (Novoa 2009, 200-202).

3. La vía continuaría hacia la confluencia entre el Najerilla y el Cárdenas, punto donde es posible que se produjera el primer cruce sobre el río principal para seguir por la margen izquierda. Otra cuestión sería la posibilidad de poder rastrear un enlace que siguiera este cauce secundario en dirección a Badarán, Estollo y Berceo. En esta zona se desarrollaron también

38 Debido a un documento del Monasterio de Valvanera fechado en 1133 donde se afirma que en Canales de la Sierra existía una ciudad antigua que denomina Segeda y que se encontraba desierta. Sobre el debate en la bibliografía: Espinosa 1981, 116-118. La Segeda que generó el conflicto del 153 a.C. y el inicio de la guerra numantina era la capital de los belos y se localiza en la Comarca de Calatayud (Zaragoza, Aragón).

39 Concluyó que se trataba de un oppidum prerromano de 11 hectáreas que pudo compartir la misma nomenclatura (Taracena 1929, 28-31).

40 BDHesp, Mon. 69, consulta 11-01-2018.
41 En contexto secundario, apareció en Arenzana de Arriba un miliario de época de Claudio que prueba una intervención en la zona tritiense entre los años 43 y 44. Según Urbano Espinosa Ruiz y M. ${ }^{a}$ Josefa Castillo Pascual, prueba la existencia de reparaciones en la vía principal. Sin embargo, el hecho de que apareciera en contexto secundario podría también corresponder este epígrafe a la construcción de los enlaces a la ciudad tritiense justo en la época donde los alfares comienzan a funcionar. Fue reconvertido, con posterioridad, en un contrapeso de un torcularium sin localizar durante la época bajoimperial (Espinosa \& Castillo 1995-1997, 105-107). 
algunos centros alfareros que produjeron hasta el mismo siglo vi d.C. ${ }^{42}$ La presencia de términos como publica via y strata en la documentación medieval referidos a este valle pueden ser indicativos de una fosilización de una posible vía romana de carácter regional. Ahora bien, estamos hablando del acceso natural al monasterio de San Millán de la Cogolla, el cenobio más importante al norte de la Demanda y del sector occidental de La Rioja por lo que el camino hacia el monasterio pudo haber sido magnificado (García 2010, doc. LXIV.1 285-286; doc. IV.b.5, 134; doc. LXLIX.1, 352-353).

4. El poblamiento rural del valle del Río Tuerto con ejemplos de torcularia y de alfares también debió contar con una calzada que enlazase esta zona con la vía principal del Najerilla ${ }^{43}$. La epigrafía de la zona ha sido estudiada por Urbano Espinosa, que recoge tres inscripciones descubiertos: una en Estollo ${ }^{44}$ y dos en San Millán de la Cogolla ${ }^{45}$, una de ellas el ya mencionado a Dercetius ${ }^{46}$ y que el autor incluye en el «Conjunto Tritiense», en su influencia más inmediata (Espinosa 1986, 12).

5. Entre el final del Cárdenas y la desembocadura del Tobía, la vía seguiría por la margen izquierda dejando en la orilla derecha los hornos de Camprovín ${ }^{47}$. En época medieval, tenemos la mención de una calzada que vendría desde Nájera (Novoa 2009, 267-267) y que sería indicio de una conexión estable entre la capital del reino homónimo y Bobadilla. A su paso por Baños de Río Tobía, la vía también daría servicios a los yacimientos de Santa Cruz y Los Bañuelos ${ }^{48}$. De la misma manera, tenemos que recordar también el interesante yacimiento de "El Villar», ya en Bobadilla, considerado como posible una posible ceca y que ha dado interesantes indicios de posible industria alfarera.

6. Referido a Anguiano, tenemos una de las menciones más interesantes dentro de la documentación medieval en el año 1014 (García 2010, doc. LXIV.1, 282-283) donde se habla de la existencia de una via maiore. Por el contrario, los testimonios hasta Canales de la Sierra son escasos. Ahora bien, tenemos la existencia de la cañada real de Santa Coloma, parte de la conocida como Segoviana ${ }^{49}$.

7. En el actual término municipal de Mansilla tenemos el embalse homónimo que oculta al antiguo pueblo. Aprovechando la margen derecha del actual pantano y del Neila, uno de los ríos que alimentan esta infraestructura hidráulica, estaba trazada la cañada real que volvía a cruzar el Najerilla a la altura de Villavelayo. Urbano Espinosa habla sobre un epígrafe perdido dedicado a Fortuna o Venus Augusta en el término Inistaza en Mansilla en un supuesto contexto de sepulcros romanos (Espinosa 1986, 102-103). Los asentamientos de Picolaicia (Viniegra de Abajo) y la Teja (Mansilla de la Sierra) también se beneficiarían del paso de

\footnotetext{
42 Vid. supra notas 23, 24, 25 y 26.

43 Se localizó un contrapeso cilíndrico de arenisca en el término de Turrios (Berceo) que formaría parte de una planta de procesamiento de vino o de aceite. Según Yolanda Peña $(2010,609)$, presenta un vaciado interno longitudinal circular con dos encajes longitudinales en su exterior. Estas características hacen de este ejemplar una pieza difícil de clasificar y, por el hecho de ser un hallazgo ocasional, no se le puede atribuir una cronología clara ni vincularlo con algún yacimiento.

${ }^{44}$ ERRioja, 39.

45 ERRioja 40 y 41.
}

46 Vid. supra nota 33.

47 Vid. supra nota 33.

48 Vid. supra notas 34 y 37.

49 Carmen Alfaro habla sobre la difícil identificación de las vías pecuarias prerromanas, aunque sí nos describe algunas de sus necesidades: cercanía a un curso fluvial o abrevaderos para las redes, existencia de pasos o vados sobre los arroyos o ríos y el aprovechamiento de puertos naturales para sortear las estribaciones montañosas (Alfaro 2001, 218). La vía que estamos estudiando bien pudo servir también para el transporte del ganado entre el Valle del Ebro y el del Duero a través del curso del Najerilla y del Pedroso. 
la calzada ${ }^{50}$. La cañada continúa su recorrido hacia Canales de la Sierra cruzando el Arroyo Toba por uno de los pasos pétreos y continuando por la margen derecha del recién nacido Najerilla, a los pies del Cerro Cividad, lugar donde hubo un poblado prerromano de cierta entidad identificado tradicionalmente como una Segeda ${ }^{51}$ y como una ceca prerromana.

8. En este término municipal, tenemos dos pasos pétreos sobre el arroyo Toba: un puente y una alcantarilla. El primero (Arrúe \& Moya 1998, 335-336) tiene unas medidas de 8,30 m de longitud, una altura de 3,15 m y una anchura variable de entre 3,50 en su acceso noroeste hasta los 4,75 m en el sureste. Está ejecutado en sillarejo con hormigón y servía para superar el cauce al sur del Cerro Peñalba. Este mismo curso estaba regulado también por una alcantarilla (Ib., 336-337), construida en mampostería con sillares irregulares y refuerzos de hormigón. Posee 9,80 m de longitud, 1,80 m de achura y $2 \mathrm{~m}$ de altura. Ha perdido las compuertas que servían para regular el caudal de agua. Se encuentra a apenas 60 metros de otro puente levantado aguas arriba sobre el mismo curso fluvial. Podía estar vinculado a un complejo minero o servir para la regulación del arroyo.

9. Ambas estructuras poseen una orientación muy similar al curso del Najerilla y miran hacia Canales de la Sierra. Según Arrúe \& Moya, se trata de un puente y una alcantarilla que han sufrido varias reformas durante su uso, si bien ven un posible origen romano a ambas infraestructuras, al menos, de los propios pasos. No podemos olvidar la epigrafía que se encontró en el entorno de Canales de la Sierra. Urbano Espinosa relaciona estas inscripciones localizadas en el Alto Najerilla con el grupo de Lara de los Infantes debido a que esta zona tendría una mejor conexión con la Meseta (Espinosa 1986, 12-13).

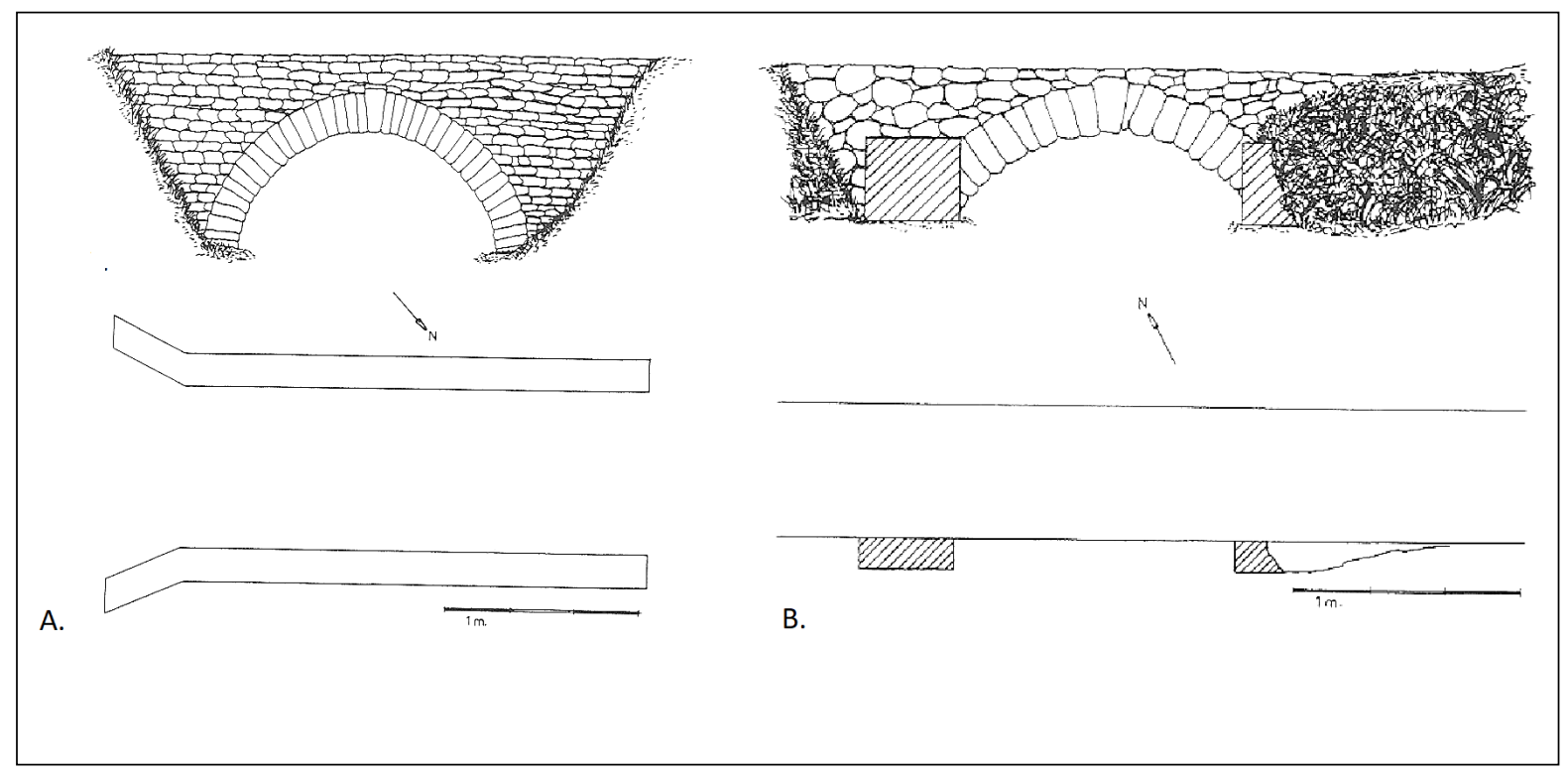

Figura 3. Pasos pétreos sobre el arroyo Toba: A. Puente y B. Alcantarilla (Fuente: Arrúe \& Moya 1998, 335337).

50 Vid. supra nota 18.

51 Vid. supra notas 39 y 40. 
Este último sector que recorre la vía por territorio de la actual Comunidad Autónoma Riojana estaría estrechamente vinculado con la explotación de los filones mineros de la región, pero también con una explotación del entorno boscoso y una fuerte actividad ganadera. Tenemos el testimonio epigráfico, ya referido, del ara a Dercetius y cómo se vincula con una divinidad solar que habitaba en la montaña.

En el valle del Iregua, se localizan también otros epígrafes que tenían que ver con divinidades vinculadas con los bosques como un ara a Silvano procedente de la ermita de San Pelayo en Nieva de Cameros, a unos $500 \mathrm{~m}$ al oeste de la localidad. Se utilizó en la construcción del edificio religioso, por lo que desconocemos dónde se encontraba originalmente. La cañada real de Santa Coloma, antes de virar hacia el oeste en Brieva de Cameros y dirigirse a Mansilla, recorre el interfluvio entre el Iregua y el Najerilla muy cerca de esta ermita, por lo que esta ara podía tener alguna vinculación con un camino para la trashumancia en época antigua. Los caminos romanos fueron utilizados con posterioridad como vías pecuarias o cañadas reales ${ }^{52}$ teniendo también un ejemplo en La Rioja: la Calzada de los Romanos entre Hormilla y la zona de San Millán de Yécora siguiendo el antiguo trazado de la vía De Italia in Hispanias (Gobierno de La Rioja 2005, 15).

Entrando ya en la provincia de Burgos, el recorrido se vuelve más complicado y tenemos dos alternativas. Existe una mención a un camino que pasaba por Canales y seguía por Huerta de Arriba en el año $1083^{53}$. La vía continuaría por el valle del Tejero/Urría pasando a los pies de la ermita de la Vega en Huerta de Abajo, yacimiento de carácter militar que ha proporcionado materiales altoimperiales ${ }^{54}$. Justo enfrente, estará el castro romanizado de La Cabeza (Escalona 1995, 172-173 y 196).

Siguiendo el Tejero, entraría en el valle del Pedroso virando hacia el sur buscando los centros prerromanos como El Castro (Castrovido/Salas de los Infantes) (Abásolo \& García 1980, 40-45). $\mathrm{Al}$ este se quedaría la atalaya bajoimperial de Cabeza de San Vicente ${ }^{55}$. En Salas de los Infantes se produciría el empalme con la vía que, procedente de Numancia, buscaba siguiendo el Arlanza el núcleo urbano de Nova Augusta.

Ahora bien, es posible que también siguiera el valle del Pedroso a través de Monterrubio de la Demanda puesto que la ermita de la Vega también posee control visual y acceso hacia el norte por el altozano de San Miguel. La Cañada de las Villas, posible trazado de la Segoviana por esta zona, parte del oeste de Canales de la Sierra y sigue el Pedroso hasta cruzar el antiguo Castro de la Cabezas a través del altozano ya mencionado y siguiendo por Cerro Mataco hasta Mojón Gordo. Si la vía seguía este mismo trazado, volvía a tener acceso al Pedroso y virando al sur buscando la zona de Salas.

Por último, en el actual término municipal de Salas de los Infantes ${ }^{56}$ existen restos de calzada que han sido fechados en época romana. Inventariados en el año 2002, son dos tramos bien diferenciados. Por un lado, está el que efectúa su recorrido por el sur de la localidad que parte del actual puente sobre el río Ciruelos y finaliza su recorrido en la ermita de San Roque con una direc-

52 Carmen Alfaro Giner pone en relación la existencia de vías pecuarias en época prerromana y romana con lugares de culto que protegieran al ganado y a los viajeros (Alfaro 2001, 226-228), por lo que el ara a Silvano, cercana a lo que luego será una Cañada Real, bien pudo ser parte de uno de estos santuarios.

53 Donación que realizó Dońa Elvira a San Millán de la Cogolla del Monasterio de San Mamés (García 2010, doc. CCCXXIII.1, 1053-1054).
54 Vid. supra nota 20.

55 Vid. supra nota 21.

56 Código IACYL 09-330-0004-06 recogido en el Plan General de Ordenación Urbana de Salas de los Infantes. Catálogo arqueológico-paleontológico. Septiembre de 2009. 
ción sur-norte. El segundo se localiza al norte, a caballo entre Salas de los Infantes y Castrovido bordeando el alto del Castro teniendo, en origen, una orientación sur-norte para luego seguir en dirección suroeste-noreste.

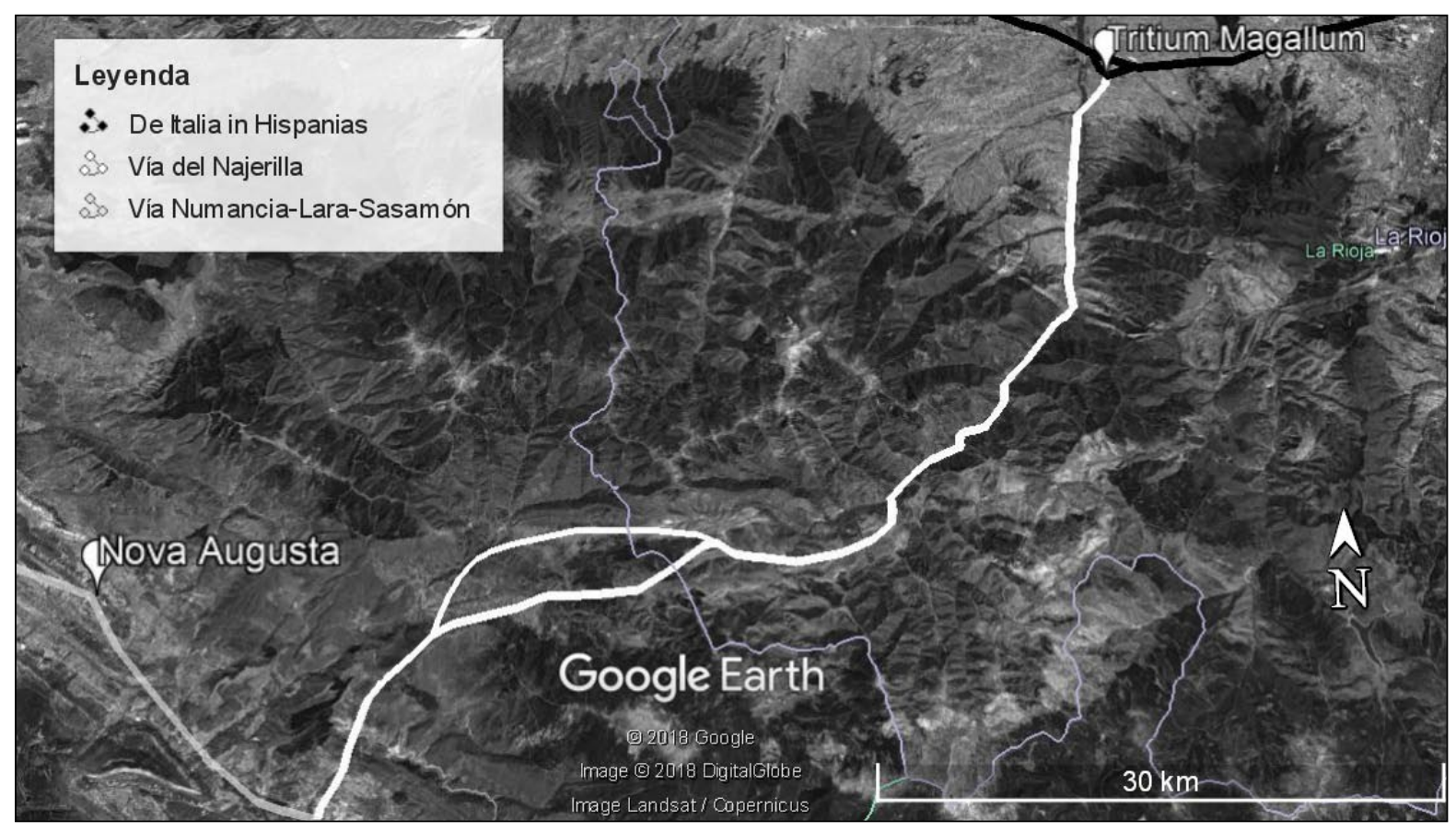

Figura 4. Entramado viario del entorno del Najerilla. Fuente: Elaboración propia/Google Earth.

\section{Historia: EVOLUCiÓN MEDIEVAL Y MODERNA DEL CAMINO}

La documentación medieval nos ayuda a rastrear la posible supervivencia de esta vía terrestre después de la caída del poder romano en la región y del paso del gobierno visigodo ${ }^{57}$. Cristina Novoa, en sus estudios sobre el entorno de Tritium Magallum, realizó una aproximación a las menciones a la caminería recogidas en la información medieval entre la zona de Nájera y Anguiano, a los pies del Sistema Ibérico. Diferenció este eje norte-sur y también una serie de caminos que seguían los cursos tributarios del Najerilla (Novoa 2009, 264-272).

La autora denominó a la vía del Najerilla como «Eje axial norte-sur» (Ib., 265-267.) y afirmó que se trataba de una vía de carácter interregional cuya reconstrucción es complicada. Los diferentes caminos mencionados en las fuentes medievales resultan inconexos en ocasiones. Sin embargo, gracias a estos datos más los recogidos por la arqueología o la epigrafía, nos podemos hacer una idea de la ruta entre Tricio y Canales de la Sierra.

57 Se ha consultado la documentación recogida en los libros becerros de San Millán de la Cogolla, de Valvanera y de Santa María La Real. 
En diferentes textos del libro Becerro de San Millán de la Cogolla y de la documentación medieval de los centros de Nuestra Señora de Valvanera (Anguiano) y de Santa María La Real (Nájera) fechados, aproximadamente, entre el 929 y el 1207, se pueden encontrar referencias a caminos tanto del curso principal del Najerilla como de los ríos secundarios bajo la terminología de via, via publica, via maiore, calçata o strata. Estas tres últimas son las que más nos interesan porque suelen sugerir el paso de un camino de época romana (García et al., 2010, 140).

De esta manera, la calzada De Italia in Hispanias ${ }^{58}$, quedó fosilizada en los textos altomedievales a su paso por Nájera, Hormilla y Alesón. La ciudad najerense heredará la preeminencia en la zona cuando la antigua civitas tritiense fue poco a poco abandonada. En un documento de Santa María La Real fechado con dudas en el 1054, se habla de las propiedades de este monasterio (Cantera 1991, doc. 13, 24 y 27). De entre ellas, tenemos una mención a una en "Nagera iuxta viam publicam" y, un poco más al oeste "duas sernas ante Formiella ad illam lacunam quas findit illa calzara integras per eorum terminos» localizado en Hormilla. Casi medio siglo después, en el Becerro Galicano de San Millán de la Cogolla (García 2010, doc. CLIV.az.1, 530), tenemos una donación de una viña en Alesoncillo: "una vinea tapiata in Alesonciello, latus calçada ad Sancti Emiliani» 59 .

Desde Nájera a Anguiano, hay multitud de referencias en documentos en los que se habla de vías que, si bien no cubren todo el curso del Najerilla, sí permiten reconstruir gran parte de su recorrido. En el entorno de Tricio tenemos una gran cantidad de información gracias a los fondos de Santa María La Real (Rodríguez 1979, doc.13, 24-29) entre los que destacan la unión de esta localidad con Arenzana de Abajo o la salida sur de Nájera.

Para la desembocadura del río Cárdenas en el Najerilla, hay nuevos testimonios en el entorno de Mahave y del propio valle del tributario. En una donación realizada al monasterio de San Millán de la Cogolla el 17 de febrero del 1050, se nos menciona una propiedad «in via Mahabe, latus flumen» (García 2010, doc. LXVI.1, 285-286). Esto nos indica que esta vía, quizá proveniente de Nájera, habría cruzado ya el río y avanzaba hacia el sur por la margen izquierda del Najerilla.

El valle del Cárdenas, acceso natural al Monasterio de San Millán de la Cogolla, cuenta también con dos menciones muy interesantes en el Becerro Galicano y ambas en Berceo: publicam viam (14 de mayo del 929) (Íb., doc. LXIV.1, 199-200) y strata (1105) (Íb., doc. IV.b.5, 134). Del mismo modo, existe una tercera referencia a strata (Ib., doc. LXLIX.1, 352-353) en San Millán, en el mismo cartulario y fechado el 12 de diciembre del 1071. Los tres términos suelen ser bases de la fosilización de una vía de origen romano, como ya hemos visto con la De Italia in Hispanias. Ahora bien, teniendo en cuenta la importancia que alcanzó el cenobio emilianense, también podía tratarse de un intento de magnificar el camino de acceso al mismo.

De nuevo en el valle del Najerilla, volvemos a tener diferentes testimonios a lo largo de la margen izquierda del mismo. En Baños del Río Tobía, en un documento del Monasterio de Valvanera fechado en el 1020, se menciona una posesión que se sitúa «in Vangos, in via de Terreno, subitus

58 Se trata de un eje viario que unía Italia con la península ibérica vía Tarragona, Zaragoza y remontaba el valle del Ebro buscando la zona del noroeste. En La Rioja, según el Itinerario de Antonino, poseía mansiones en Graccurris (Alfaro), Calagurris Iulia (Calahorra), Vareia (Varea, Logrońo), Tritium Magallum (Tricio) y Libia (Herramelluri). It. Ant. 392.2-394.3.

\footnotetext{
59 Cristina Novoa, además de mencionar estos tres documentos, reconstruye también el desvío hacia la antigua ciudad tritiense con una vía de Tricio a Alesón (Santa María La Real, doc. 13., 24-29) y de Santa Eugenia a Tricio (Rodríguez 1979, doc. 14, 57-65).
} 
carrera» (Ib., doc. 1, 17-18). Lo que nos indica el inicio de una vía hacia Terreno (posiblemente en algún lugar de Badarán) y que la propiedad se situaba en Baños. Este mismo término municipal también se menciona en el 1086 (Ib., doc. CCXXX.e.1, 832) como parte de una vía en el Becerro Galicano.

Bobadilla posee un número nutrido de referencias dentro de los documentos medievales. Como ejemplo, podemos poner documentos fechados en el 1085 (Ib., doc. CXXXI.c.1, 424) y en el 1086 (Ib., doc. CXXXI.b.3, 423) dentro del Becerro Galicano u otro del 1074 (Cantera 1991, doc. 19, 37-38) del archivo de Santa María La Real. Sin embargo, nos interesan dos testimonios. En el 1010, se nos habla de una "carrera qui perguit ad Sancti Victoris» (García 2010, doc. LXI.1, 277) dentro del lote de propiedades que el presbítero Sancho de Bobadilla donó a San Millán de la Cogolla. Y en el 1104, en un intercambio de tierras entre Munio Cristóbal y los monjes emilianenses, se menciona en el término de Bobadilla una vía que venía desde Nájera (Ib., doc. CXXXI.d.1, 432). Llegando al interfluvio entre el Río Tobía y el Najerilla y avanzando hacia Anguiano, volvemos a tener numerosos testimonios sobre la red viaria en época medieval. Hacia el tributario se puede encontrar con conexiones con Certum, margen izquierda del Tobía, y con Matute, que se sitúa en la margen derecha con el río principal ${ }^{60}$.

En Anguiano hay varias menciones a senderos, vías y caminos. En el documento del 1014 en donde se certifica cómo Sancho III el Mayor agrega el Monasterio de San Pedro a los dominios de San Millán (García 2010, doc. LXIV.1, 282-283), observamos cómo las propiedades del primero incluyen unos terrenos junto a la vía de Torca o junto a la via maiore de Fascias, ambos en el actual término municipal de Anguiano. Este último es interesante porque puede evidenciar el pasado romano de la misma o, al menos, una mayor relevancia. En 1054 (Cantera 1991, doc. 13, 28-29), 1079 (García 2010, doc. 109. 105-106) y 1081 (Ib., doc. 134, 127-128) volvemos a tener nuevas referencias de vías en el entorno de la localidad anguianiega de vías.

Más allá de Anguiano, las referencias a vías en la documentación medieval son difusas, salvo por una breve mención a una carretera en el actual territorio de Canales de la Sierra. Se trata de la donación del Monasterio de San Mamés de Huerta de Arriba a San Millán de la Cogolla por parte de Dońa Elvira y que se fecha en el 1083 (Ib., doc. CCCXXIII.1, 1053-1054).

Ahora bien, la comunicación por el valle del Najerilla estuvo activa porque fue testigo del paso del caudillo musulmán Almanzor. El 21 de mayo del 1002, partió de Córdoba para realizar una nueva campaña contra los cristianos del norte. Su ejército pasó por Clunia, Salas de los Infantes y llegó a Canales de la Sierra utilizando el valle del río Pedroso (Castellanos 2003,137-140). El curso del Najerilla le sirvió para entrar en territorio riojano e incendiar el monasterio de San Millán de

60 De esta manera, un documento fechado en el 1020 del Becerro Galicano de San Millán de la Cogolla habla de cómo Sancho III el Mayor confirma la donación al cenobio emilianense del Monasterio de San Cristobal de Tobía y parte de las propiedades cedidas se encuentran "super carrera inter Matute et Villa Nova», es decir, entre la actual localidad de Matute y Villa Nova, término situado al norte de Anguiano (García 2010, doc. LIII.1, 256-257).

Igualmente, en el listado de bienes de Santa María La Real, fechado con dudas en el 1054, se recoge una propiedad que se sitúa junto a «viam de Certum et de Matut ad Nazariellan» y "via de Certum et Matut ad Villam Novam». La primera enlazaba el Tobía directamente con el Najerilla siguiendo, quizá, el curso tributario mientras que la segunda tendría su final en Villa Nova. Para su consulta, Cantera 1991, doc. 13, 28.

Por último, entre Matute y Anguiano, discurría una vía que se denomina como el monasterio por donde pasaba: via de Sancti Petri y que está atestiguada el 25 de marzo del 1080 (García 1985, doc 124, 118-119) o el 6 de abril el 1080 ( $I b$. , doc. 125, 119-120) dentro del repertorio documental procedente del santuario de Nuestra Señora de Valvanera. 
la Cogolla. Posteriormente regresó de nuevo a la Meseta utilizando el paso de Santa Inés (Ib., 140) para fallecer por enfermedad en Medinaceli el 10 de agosto ${ }^{61}$.

Se ha puesto en duda que Almanzor incendiase el monasterio de San Millán de la Cogolla (Ubieto 1973, 194-200), por lo que debemos acudir a la arqueología para poder buscar alguna respuesta. Luis Caballero Zoreda daba a conocer la lectura de paramentos de la iglesia de San Millán de la Cogolla de Suso efectuada en el año 2002. En la denominada «Etapa II Mozárabe. Fase IIB», habla de la existencia de evidencias de un incendio entre el primitivo edificio y las posteriores ampliaciones mozárabes y protorrománicas (Caballero 2004, 42-43).

El autor evidencia que las fechas manejadas pueden ser coincidentes con el ataque musulmán, puesto que, con posterioridad, se realizó una restauración y se sitúa antes de las luchas entre los hijos de Sancho III «el Mayor» puesto que se le atribuye a este monarca la ampliación de época protorrománica $(I b ., 43)$. Por lo tanto, es posible que el ataque contra el cenobio emilianense de Almanzor se produjera, pero el autor no se atreve a afirmarlo en el estado actual de las investigaciones.

El entorno de la Demanda, durante la Edad Media fue uno de los puntos de origen de la trashumancia que llevaba las reses hacia el sur. De hecho, cuatro de las principales cañadas reales poseen su origen en La Rioja. Una de ellas, la denominada como "Segoviana», en su tramo conocido como el de "Santa Coloma», tenía su recorrido por el sector suroccidental riojano (Gobierno de La Rioja 2005, 15).

Es interesante para este trabajo la solución que tenía para enlazar la Sierra del Camero Nuevo con el entorno de Mansilla y el paso de Canales. Lo realizaba por Ventrosa hasta Viniegra de Abajo desde donde enlazaba con el Najerilla pero, en lugar de seguir su cauce, se separa rumbo sur evitando los cerros encajados del río. A partir de Villavelayo, volvía a seguir el cauce najerense hasta llegar a Canales de la Sierra cruzando el arroyo Toba sobre el que, como ya hemos visto, se conserva un puente y una alcantarilla con posible origen romano. Posteriormente seguía por la actual provincia de Burgos a través de Huerta de Arriba y Huerta de Abajo.

\section{Conclusiones}

La vía del Najerilla, entre Tritium Magallum y el entorno de Nova Augusta, constituyó la unión directa entre el valle del Ebro y el del Duero desde época prerromana y se desarrolló por una zona, la Sierra de la Demanda, con un potencial económico de carácter minero, ganadero y comercial.

Las minas proporcionaron el metal con el que se realizaron las monedas que emitieron las tres cecas que podemos localizar en el trazado de la vía y tenían que ser también fuente de riqueza para sus habitantes. Poblados que alcanzaron un gran desarrollo y cuya unión a lo largo del valle parece un hecho. Sus moradores se encargaron de criar reses para su propio consumo y comercio de los excedentes alimenticios.

Una vía que se mantuvo en época romana. Cluniense era Lucio Memmio Probo, gramático del municipio tritiense que pudo llegar utilizando el Najerilla. La existencia de una institución educa-

61 Según el historiador Ibn Idhari al-Marrakusi «Murió en la noche del 10 de agosto del 1002. El día de su muerte estaban con él sus hijos Abd-al-Malik y Abd-al-Rahman Sanchol. Había estado en el gobierno, desde que accedió al cargo de hachib hasta que murió,
25 años y 44 días. Realizó 57 expediciones en persona y en la mayoría de ellas le afligió la enfermedad de la Gota ¡Dios enaltecido sea, salve a él y a nosotros!» Texto recogido por Juan Castellanos (Ib., 140). 
tiva en la ciudad es una prueba de la riqueza que llegó a alcanzar gracias a su producción cerámica que tenía la posibilidad de ser exportaba debido a la estratégica situación de la ciudad como nudo de comunicaciones. Por la vía De Italia in Hispanias alcanzaba la zona del Noroeste, Caesaraugusta y el Levante; gracias a las conexiones "Galiana» llegaba a las calzadas navarras que lo conectaban con Pompaelo, el puerto de Oiasso y la Galia; y el curso del Najerilla le servía para conectarse con focos productores menores en los tributarios como el Cárdenas y con la Meseta gracias al paso de Canales de la Sierra. El comercio de cerámica tritiense inundó la Meseta dominando un mercado tan importante como Clunia, la capital conventual, y sirvió como acicate para que florecieran talleres propios en el entorno del Arlanza a partir del siglo iv d.C., por lo menos.

Ya en época medieval, se puede rastrear gran parte de su trazado entre Nájera, foco principal tras la decadencia de Tricio, Anguiano y Canales y cómo sirvió para campañas militares como la de Almanzor a principios del siglo xI. Una vía que, en parte, se mantuvo como Cańada Real y que sirvió para dar acceso a los importantes centros monásticos de San Millán de la Cogolla, N. ${ }^{a}$ S. ${ }^{a}$ de Valvanera y, mediante una conexión con el río Tuerto, con Santa María de San Salvador de Cańas. Del mismo modo, ponía en relación estos cenobios con San Pedro de Arlanza y Santo Domingo de Silos.

Desgraciadamente, no tenemos testimonios epigráficos que nos den fe de una intervención imperial o de deidades vinculadas con los viajes (Mercurio, por ejemplo) o las calzadas (como pueden ser los Lares Viales). Ahora bien, las vinculaciones de los conjuntos epigráficos que hemos podido ver descritos de una manera somera son claros: el núcleo pelendón o de Canales mira hacia el Duero y al extraordinario foco de Lara de los Infantes, mientras que los testimonios del valle del Cárdenas se relacionan con Tritium Magallum. Una vía que sobrevive actualmente, pese al paso de los siglos, en el trazado de las carreteras LR-113 y BU-825.

\section{Bibliografía}

Aвásolo, J. A., 1978, Las vías romanas de Clunia, Burgos: Servicio de Investigaciones Arqueológicas de la Diputación Provincial de Burgos.

Aвásolo, J. A., 2007, «Lara de los Infantes, Municipium a pesar de la arqueología», en: M. Navarro \& J. J. Palao (eds), Villes et territoires dans le bassin du Douro à l'epoque romaine, Burdeos: Ausonius Editions 17, 125-148.

Abásolo, J. A., \& R. García, 1980, Carta arqueológica de la provincia de Burgos. Partido judicial de Salas de los Infantes, Burgos: Diputación Provincial.

Alfaro, C., 2001, «Vías pecuarias y romanización en la Península Ibérica», en: J. Gómez-Pantoja (ed), Los rebaños de Gerión. Pastores y trashumancia en Iberia antigua y medieval, Madrid: Collection de la Casa Velázquez vol. 71, 215-231.

Alonso, C., 2015, La vía romana De Italia in Hispanias/Item ab Asturica Tarracone a su paso por La Rioja: desarrollo topográfico, evidencias estructurales y modelo constructivo, Madrid: UNED.

Alonso, C., \& J. Jiménez, 2015, «La zona alfarera de Tricio (La Rioja): novedades sobre su dimensión, caracterización y gestión», en: M. I. Fernández, P. Ruiz \& M. V. Peinado (ed), Terra Sigillata Hispánica. 50 años de investigaciones, Roma: Edizioni Quasar di Severino Tognon, 117-126.

ArIAs, G., 1965, «¿Una calzada Jaca-Rioja?», El miliario extravagante 8, 181-189.

Ariño, E., \& M. A. Magalión, 1991-1992, «Problemas de trazado de las vías romanas en la provincia de La Rioja», Zephyrus: revista de prehistoria y arqueología 44-45, 423-455.

Ariño, E., \& C. NovoA, 2007, "Fotografía aérea en La Rioja Alta. Tritium Magallum (Tricio) y Libia (Herramelluri)», Revista de Arqueología, año 28, 315, 54-63. 
ArmendÁriz, J., \& J. VelazA, 2006, «Dos miliarios romanos en Arellano: contribución al estudio de las comunicaciones viarias en época romana en Navarra, Trabajos de Arqueología Navarra 19, 109-126.

Arrúe, B., \& J. G. Moya, 1998, Catálogo de puentes anteriores a 1800. La Rioja, Logrońo: Instituto de Estudios Riojanos.

Ayllón, R., 2015, Cuevas, bosques y montañas sagradas de Celtiberia (ss. II a.C.-II d.C.): entre la transformación y el abandono, Barcelona: Universidad de Barcelona.

Caballero, L., 2004, «La iglesia de San Millán de la Cogolla de Suso. Lectura de paramentos 2002», en: I. Gil-Díez (coord.), Arte medieval en La Rioja: prerrománico y románico. VIII Jornadas de Arte y Patrimonio Regional (Logroño, 29 y 30 de noviembre de 2002), Logrońo: Instituto de Estudios Riojanos, 13-94.

Cantera, M., 1991, Colección documental de Santa María La Real de Nájera. Tomo I (siglos X-XIV), San Sebastián: Eusko Ikaskuntza.

Castellanos, J., 2003, Geoestrategia en la España Musulmana. Las campañas militares de Almanzor, Madrid: Ministerio de Defensa.

Castellanos, S., 1999, Hagiografía y sociedad en la Hispania visigoda. La Vita Aemiliani y el actual territorio riojano (siglo VI), Logroño: Instituto de Estudios Riojanos.

Castellanos, S., 2011, Poder social, aristocracias y hombre santo en la Hispania Visigoda. La Vita Aemiliani de Braulio de Zaragoza, Logrońo: Universidad de La Rioja.

Castillo, M. J., \& U. Espinosa, 1995-1997, «Novedades epigráficas en el Ebro Medio», Lucentum, 14-16, 101-112.

Ceniceros, J., 2017, «Museo Najerense: sección de arqueología», Boletín del Museo Arqueológico Nacional 35/2017, 1665-1673.

De las Heras, M.a de los Á., 1988, «Existencia de un alfar romano en el término de «San Cruz» de Baños de Río Tobía (La Rioja)", Berceo 114-115, 61-104.

Domergue, C., 1990, Les mines de la Péninsule Ibérique dans l'antiquité romaine, École Française de Rome.

Escalona, J., 1995, Transformaciones sociales y organización del espacio en el Alfoz de Lara en la Alta Edad Media, Madrid: Universidad Complutense.

Espinosa, U., 1981, Estudios de bibliografía arqueológica riojana: prehistoria e historia antigua, Logroño: Instituto de Estudios Riojanos.

Espinosa, U., 1986, Epigrafía romana de La Rioja, Logroño: Instituto de Estudios Riojanos.

Espinosa, U., 1988, «Riqueza mobiliaria y promoción política: los Mamili de Tritium Magallum», Gerión 6, 263-272.

Espinosa, U., 1994a, «Bajo la República Romana», en: J. Á. Sesma Muñoz (coord. gen.), Historia de la Ciudad de Logroño. Tomo 1, Logroño: Ayuntamiento de Logroño e Ibercaja, 99-108.

Espinosa, U., 1994b, "Ordenación territorial», en: J. Á. Sesma Muñoz (coord. gen.), Historia de la Ciudad de Logroño. Tomo 1, Logroño: Ayuntamiento de Logroño e Ibercaja, 115-146.

Espinosa, U., \& M. J. Castillo, 1995-1997, «Novedades epigráficas en el medio Ebro (La Rioja)», Lucentum 14-16, 101-112.

EzQuivela, I. J., 2009, «La minería en el alto Najerilla», Piedra de Rayo 31, 60-71.

Fernández, M. C., 2001, El reino de Nájera (1035-1076). Población, economía y poder, Logroño: Instituto de Estudios Riojanos.

Garabito, T., 1978, Los alfares romanos riojanos. Producción y comercialización, Madrid: CSIC-Instituto Español de Prehistoria, Servicios de Publicaciones de la Universidad de Valladolid y Diputación provincial de Logroño.

García, F., 2010, El Becerro Galicano de San Millán de la Cogolla, Logroño: Cilengua.

García, J. J., D. Peterson, J. García \& L. García, 2010, «Introducción al conocimiento de la viaria romana de la Cuenca del Duero a través de la documentación altomedieval», en: Las técnicas y construcciones en la ingeniería romana, Madrid: Fundación de la Ingeniería Técnica de Obras Públicas.

García, F. J., 1985, Documentación medieval del Monasterio de Valvanera (siglos XI a XIII), Zaragoza: Anúbar Ediciones. 
Gimeno, H., \& M. Mayer, 1993, «Una propuesta de identificación epigráfica: Lara de los Infantes/Nova Augusta», Chiron 23, 14-19.

Gobierno de La Rioja, 2005, "Caminos de Pastores. Gestión de las vías pecuarias en La Rioja», Páginas de información ambiental 21, 313-321.

Granado, I., 1993, La Rioja como sistema. Vol I: La Rioja Natural, Logroño: Gobierno de La Rioja.

Íñ Igo, L., \& M. M. Martínez, 2002, «Nuevo alfar de Terra Sigillata Hispánica Tardía en el Valle Medio del Najerilla (Cañas, La Rioja)», Iberia. Revista de la Antigüedad 5, 217-274.

Madroñero, A., 1985, "Interpretación inicial de los restos de una estación siderúrgica aparecidos en el entorno del santuario de Ntra. Sra. de la Valvanera (Rioja)», Revista Técnica Metalúrica, julio-agosto, 20-31.

Magallón, M. A., 1983, «La red viaria romana en La Rioja», Cuadernos de investigación: Historia t. 9, fasc. 1, 153-166.

Martín, M. A., \& J. G. Moya, 1972, «El puente Mantible», Estudios de Arqueología Alavesa 5, 165-182.

Martínez, M. M., \& S. Vitores, 1999, "Yacimiento romanos en los entornos de Berceo y Badarán», Iberia. Revista de la Antigüedad 2, 239-273.

Martínez, M. M., \& S. Vitores, 2000, «Nuevos alfares de Terra Sigillata Hispánica Tardía de Tritium Magallum (Badarán y Berceo, La Rioja)», Iberia. Revista de la Antigüedad 3, 333-372.

Moreno, I., 2004, «Es romano el puente Mantible? El camino de Pamplona Nájera, de Sancho el Mayor», Piedra de rayo: Riojana de cultura popular, 12, 66-72.

Moreno, I., 2011-2017a, Vía romana de Numancia a Lara de los Infantes y a Sasamón. 148 km, www. viasromanas.net/ (Consultado el 17/01/2018).

Moreno, I., 2011-2017b, Vía romana de Osma a Clunia. 36 km, www.viasromanas.net/ (Consultado el $17 / 01 / 2018)$.

Novoa, C., 2009. Arqueología del paisaje y producción cerámica: los alfares del valle del Najerilla (La Rioja) y su distribución espacial, Tesis doctoral, Universidad de Salamanca.

Nuin, J., M. R. Mateo \& A. Duró, 2016, «Noticia del hallazgo de la Calzada del Arga», Trabajos de Arqueología Navarra 28, 289-297.

Ochagavía, D., 1951, «Notas para la historia minero-fabril riojana», Berceo 21, 469-510.

Pascual, M. P., \& H. Pascual, 1984, Carta arqueológica de La Rioja I. El Cidacos, Calahorra, Amigos de la Historia de Calahorra.

Pascual, M. P., P. Rioja \& P. García, 2000, «El centro alfarero de Sobrevilla. Badarán. La Rioja», La exégesis como instrumento de creación cultural. El testimonio de las obras de Gregorio de Elbira, Murcia: Antigüedad y Cristianismo 17, 291-312.

PAZ, J. A., 2008. «Las producciones de terra sigillata hispánica intermedia y tardía», en: D. Bernal, A. Ribera (coords.) Cerámicas hispanorromanas: un estado de la cuestión, Cadiz: Universidad de Cádiz, 497-539.

Peña, Y., 2010, Torcularia. La producción de vino y aceite en Hispania. Catálogo de yacimientos analizados, Tarragona: UNED.

Pérez de Laborda, A., 1985, "Una calzada romana a lo largo del valle del Arga», Trabajos de Arqueología Navarra 4, 144-155.

Pérez, F. 2014, «Los centros de producción de la Terra Sigillata Hispánica tardía. Antiguos y nuevos centros, hornos y estructuras asociadas», Oppidum. Cuadernos de Investigación 10, 147-176.

Pradales, D., \& J. Gómez, 2003, «La arqueología romana en la provincia de Burgos. Orígenes y desarrollo (II)», Boletín de la Institución Fernán González 226, 61-85.

Roldán, J. M., 1975, Itineraria Hispana. Fuentes antiguas para el estudio de las vías romanas en la Peninsula Ibérica, Valladolid: Universidad de Valladolid.

Roldán, J. M., \& C. Caballero, 2014, «Itinera hispana. Estudio de las vías romanas en Hispania a partir del Itinerario de Antonino, el Anónimo de Rávena y los Vasos de Vicarello», El nuevo miliario 14, 10253.

Romera, A., 2012, Conexión con la Meseta desde el Ebro Medio de las vías romanas como base de la malla territorial de España, Madrid: Universidad Politécnica de Madrid. 
Romero, M. V., \& F. Romero, 2016, «La Sigillata Hispánica de Uxama Argaela y Tritium Magallum. Reflexiones acerca de las relaciones entre ambos centros productores", Anejos a Cuadernos de Prehistoria y Arqueología de la Universidad Autónoma de Madrid, 2, 299-314.

Sáenz, J. C., 1995, «Los alfares de época tardorromana del valle del río Najerilla (siglos III-VI d.C.)», Berceo $128,113-157$.

SÁenz, M. P., 1998, «El complejo alfarero de Tritium Magallum (La Rioja): alfares altoimperiales», en: M. I. Fernández García (ed.), Terra sigillata hispánica: Estado actual de la investigación, Jaén: Servicio de Publicaciones de la Universidad de Jaén, 125-161.

SÁnchez-Moreno, E., 2010, «The late prehistory and early history of the region: the Najerilla valley within the context of the Upper Ebro and Iberian Systems», en: B. Cunliffe, G. Lock, A valley in La Rioja: The Najerilla Project, Oxford: Oxford University School of Archaeology, 207-250.

Taracena, B., 1929, "Excavaciones en las provincias de Soria y Logrońo», Junta Superior de Excavaciones y Antigüedades, año 5, 28-31.

Tuset, F., \& J. BuxedA, 1995, «La cerámica Terra Sigillata Hispánica Avanzada (TSHA) de Clunia: segunda mitad del siglo II-siglo III d.C.», Actas del I Congreso de Arqueología Peninsular. Trabalhos de Antropologia e Etnologia, Oporto, 355-367.

Ubieto, A., 1973, «Los primeros años del Monasterio de San Millán», Príncipe de Viana 34, 181-200. 